\title{
REPRESENTAÇÕES SOCIOCULTURAIS E ECONÔMICAS DO MAROLO NO SUL DE MINAS GERAIS
}

Eliane Garcia REZENDE ${ }^{1}$

Nadja Maria Gomes MURTA ${ }^{2}$

Marcelo Lacerda REZENDE ${ }^{3}$

Nayara Cunha Junqueira MORAIS ${ }^{4}$

Maria Helena Vilas Boas CONCONE

\begin{abstract}
${ }^{1}$ Professora adjunta da Universidade Federal de Alfenas (MG). Possui graduação em Nutrição e em Farmácia Bioquímica pela Universidade Federal de Ouro Preto. Doutora em Ciências Sociais pela PUC/SP, área de antropologia e Mestre na área de Epidemiologia, pela Universidade Federal de Minas Gerais. elianeg1202@gmail.com

${ }^{2}$ Professora Adjunta da Universidade Federal dos Vales do Jequitinhonha e Mucuri Nutricionista. Doutora em Ciências Sociais pela PUC/SP. nadjamurta@gmail.com

${ }^{3}$ Professor na Unifal-MG. Doutor em economia aplicada pela ESALQ/USP. marcelo.l.rezende@gmail.com

${ }^{4}$ Discente bolsista da Unifal-MG. najunqueira@yahoo.com.br

${ }^{5}$ Professora Titular do Departamento de Antropologia; Orientadora nos Programas de Estudos Pós-Graduados em Ciências Sociais e no PEPG em Gerontologia, da PUC/SP. trcconcone@ yahoo.com.br
\end{abstract}

Recebido em: 04/10/2015 - Aprovado em: 15/04/2016 - Disponibilizado em: 30/07/2016

\section{Resumo}

Os alimentos guardam na vida social expressões simbólicas, traduzindo sentimentos de alegria ou mágoa, ou expressando congratulações em ocasiões vividas pelo grupo familiar ou de amizade, e também expressões de regionalidade e identidade local. Cidades do Brasil Central e do Sul de Minas Gerais nas regiões de cerrados guardam lembrança de cavaleiros em época de Semana Santa, levando balaios carregados de marolo que eram vendidos em ruas e em praças, época da fruta madura. Este estudo descreve a relação do homem com o Marolo (Annona crassiflora Mart.; araticum - fruta do cerrado), sua inserção na vida sociocultural e econômica de famílias do Sul de Minas Gerais. É um estudo descritivo exploratório e qualitativo. Utilizamos o critério de saturação de dados para definir o número de participantes; realizamos nove entrevistas, buscando seguir a cadeia produtiva da fruta, incluindo produtores, comerciantes e cultivadores de mudas do maroleiro. O "trabalhar com o Marolo" segue tradição, oferece identidade as famílias, e todos se envolvem desde a colheita à comercialização dos produtos. A fruta é re-significada na região como patrimônio cultural, faz interface com a religião na época da safra, renova sociabilidade na comercialização das frutas e derivados e torna os "maroleiros" símbolo da cidade de Paraguaçu (MG).

Palavras-chave: Cultura. Representação social. Marolo. Antropologia. Economia.

\section{Socialcultural and economic representations of Marolo in southern Minas Gerais}

\begin{abstract}
Foods keep symbolic expressions in social life, translating feelings of joy or sorrow, or expressing congratulations in occasions lived by the family or the group of friends, and also expressions of regional and local identity. Cities in Central Brazil and in South Minas Gerais, in the region of savannahs keep the memories of horsemen during Easter, carrying hampers full of marolo which were sold on the streets and in the squares, times of ripe fruit. This study describes the relationship between men and Marolo (Annona crassiflora Mart.; araticum - fruit from the savannah), its insertion in the social, cultural and economic life of the families of the South Minas Gerais. It is a descriptive, exploratory and qualitative study. We used the criterion of data saturation to define the number of participants: we have performed nine interviews, searching to follow the productive chain of the fruit, including producers, tradesmen and growers of marolo seedings. "working with Marolo", follows tradition, offers identity to families, and everyone gets involved from the harvest to the trading of the fruit. The fruit is re-signified in the region as cultural heritage, it interfaces with religion during the harvest, it renews sociability during commercialization of the fruit and derivatives and turnes the "marolo traders" into symbols of the town of Paraguaçu (MG).
\end{abstract}

Keywords: Culture. Social representation. Marolo. Anthropology. Economics. 


\section{Introdução}

Nada nos é tão relevante na cultura como os significados dos alimentos. Para Braga (2004, p.39), "nenhum alimento está livre das associações culturais" e muitas vezes conferem "identidades sociais". Seja no âmbito nacional, como o arroz com feijão brasileiro, ou no plano regional, a exemplo do pão-de-queijo de Minas Gerais ou do acarajé da Bahia, eles podem funcionar como “demarcadores identitários" (BRAGA, 2004).

No Brasil, essa conquista de relações com o homem, com as cidades e a história, realiza uma viagem interessante que vai da botânica aos costumes populares, das lendas aos usos na medicina, dos aspectos econômicos à política, da religião à arte e à literatura.

O Marolo (Annona crassiflora Mart.) fruta do cerrado, com distribuição atualmente restrita a Minas Gerais e Goiás, é expressão alimentar, cultural e de valor econômico na região (DELLA LUCIA, et al. 2011). Tal relevância vem desde o período colonial, quando aparece em passagens literárias clássicas, como se verifica em Cardim $^{\mathrm{i}}$ desde 1584, e no “Grandes Sertões” de Guimarães Rosa.

"Araticû he hua aruore do tamanho de laranjeira, e maior, a folha parece de cidreiras ou limoeiro, he aruore fresca, e graciosa, dá hua fruita da feição e tamanho de pinhas, e cheira be tem arezoada gosto, e he fruita desenfastiada" (CARDIM, 1925).

"Pois, várias viagens, ele veio ao Curralinho, vender bois e mais outros negócios - e trazia para mim caixetas de doce de buriti ou de araticum, requeijão e marmeladas" (GUIMARÃES ROSA, 1994, p. 155).
$\mathrm{Na}$ região Sul Mineira são comuns os sorveteiros, produtores artesanais de licor, e doceiros que utilizam a fruta. Essa inserção nos usos e costumes populares, sua origem, suas características e relações com o homem, com as cidades e com a história, percorrendo das lendas até a alta tecnologia, da economia à religião, da política à arte e à literatura, é objeto relevante para estudo.

$\mathrm{O}$ presente trabalho objetivou investigar as relações nos usos do Marolo, buscando interpretar na cultura local sua valorização. Esse estudo, portanto, irá descrever, e analisar, as representações sociais do Marolo em famílias que usufruem de sua safra e mantêm forte identidade com ela na região Sul de Minas Gerais.

\section{Percurso metodológico}

Buscando os objetivos foi realizada pesquisa qualitativa, com uso de entrevistas abertas, tratando-se de um estudo descritivo exploratório. As entrevistas com perguntas norteadoras ofereceram flexibilidade e permitiram interação com o entrevistado, possibilitando explorar melhor as informações transmitidas (SELAU, 2004; MARTINS, 2004). Relacionou-se os aspectos sociais e culturais, que permeiam a relação entre grupos populacionais, o ambiente, o alimento, a planta e o fruto.

As informações foram coletadas nas cidades de Paraguaçu, Machado e Alfenas, região de cerrado, onde há venda de Marolo nas 
calçadas, feiras livres e rodovias. Paraguaçu foi escolhida como ponto inicial do estudo, por apresentar em sua história importante referência em relação à presença do Marolo.

Do total de entrevistas foram selecionadas nove (melhor gravação e informantes de diferentes classes sociais), sendo cinco entrevistados do gênero masculino e quatro feminino, entre 2009, 2010 e 2011, abarcando o período de safra e buscando seguir a cadeia produtiva da fruta, incluindo produtores, comerciantes, processadores e cultivadores de mudas do maroleiro. As entrevistas foram transcritas, corrigindo-se pouco para o português vigente, na perspectiva de preservar a terminologia utilizada pelo informante, pois as expressões nativas reforçaram os significados culturais da fruta.

O referencial teórico para análise dos conteúdos foi o materialismo sócio-histórico, no qual o homem é considerado na sua forma plural, mas sujeitado ao contexto no qual está inserido, ou seja, o sujeito como datado, histórico e marcado pelo seu trabalho e sua cultura (VYGOTSKY, 1991; AGUIAR, OZELLA, 2013), sendo a linguagem a sua materialidade.

\section{A cultura: tradição e culinária com Marolo}

Para Geertz (1989, p. 103) a cultura é "um padrão de significados transmitido historicamente, incorporado em símbolos, um sistema de concepções herdadas expressas em formas simbólicas por meio das quais os homens comunicam, perpetuam e desenvolvem seu conhecimento e suas atividades em relação à vida". Nenhum alimento está livre de significados culturais atribuídos por cada grupo social, ocorrendo às frutas nativas, às preparações que decorrem dessa relação homem/alimento, que revelam condições ou transformações sociais importantíssimas.

No cerrado brasileiro existe na lembrança de seus habitantes os cavalos com cargueiros de balaios carregados de Marolo em época de Semana Santa - geralmente em março/abril, conforme tradição católica - é época da fruta madura, vendida nas ruas e praças (DELLA LUCIA, 2013). Essa tradição familiar move todo o processo de produção e comercialização da fruta e seus derivados. Ocorre, nesse sistema, uma aproximação da divisão de trabalho por gênero e idade, como culturalmente foi determinado no passado: as crianças ajudam na coleta do fruto, as mulheres se encarregam de fazer os doces, os sorvetes e os licores e os homens são responsáveis pela coleta e comercialização dos frutos e produtos. Dos entrevistados, $90 \%$ se referiram a essa dinâmica organizativa de trabalho.

"Isso aí é uma tradição que vem do meu avô, do meu avô passou pro meu pai, do meu pai passou pro meu irmão mais velho e passou pra nós e nós estamos com ele até hoje, faz muito tempo. Desde a idade de sete anos já conhecia o Marolo, catava Marolo pro meu pai, pra ele vender, eu catava pros meus irmãos vender e dos meus irmãos foi passando pra nós mais novos pra gente vender também. E vamos indo, de pai passando pra filho" (D, vendedor e produtor). 
"Quem mexia com Marolo é a família do meu marido. A irmã, o cunhado, é que agora eles não estão aqui, fecharam a barraca hoje. Tinha várias barracas, a maior parte do pessoal que estava aqui era mais entre família' (P, vendedora).

Na região estudada, o município de Paraguaçu apresenta o Marolo fortemente considerado na alimentação e na cultura popular, conferindo identidade especial e interagindo com as cidades circunvizinhas. Relatos da história da cidade, que datam de tempos de ocupação territorial, descrevem a fruta como produto nativo do bioma cerrado, sempre ligado aos movimentos culturais da cidade. $\mathrm{O} \mathrm{Sr} \mathrm{S}$ (produtor e vendedor) relatou que agricultores dos distritos rurais, "no princípio" (se referindo aos tempos idos), levavam carregamentos de Marolo a municípios vizinhos a cavalo, mais tarde substituídos por caminhões. Prado (2004) relata que: "Há algum tempo atrás, Paraguaçu era um dos grandes municípios produtores de Marolo da região - éramos até conhecidos por 'maroleiros'".

Cenas de vendedores oferecendo o fruto, na beira das estradas sempre foram comuns, sendo tradição festas tais como: provas de enduro, festejos de quermesse na Praça da Igreja com doces e licores da fruta, além da presença no passado de um bloco carnavalesco que levava o nome "Marolo Atômico". O brasão da cidade, criado em 1987 por Yelo Evani Prado, traz o ramo de maroleiro, ao lado do café, como um dos símbolos na bandeira da cidade.
Em 1912, a família Andrade iniciou a fabricação de licor e doces para venda em sua mercearia, divulgando a fruta e seu sabor para a região Sudeste do Brasil. Dona M (dessa família) mostra com orgulho os dados do caderno de contabilidade de seu avô, onde são relatados os números de litros de licor com seus valores antigos, vendidos para o Rio de Janeiro. Em 2009, seus descendentes registraram o licor e doces de Marolo como patrimônio municipal ${ }^{\mathrm{ii}}$.

A solicitação de preservação dos chamados "bens culturais de natureza imaterial" na qualidade de "patrimônio intangível"iii está crescente, e nos últimos anos vem utilizando a perspectiva antropológica para desvendar a maneira pela qual as tradições, as criações, as festas, as datas, os trajes típicos, dentre outros símbolos podem servir como patrimônios locais, regionais ou nacionais. Nessa linha o patrimônio gustativo da sociedade, torna-se símbolo patrimonial, buscando: as tradições culinárias junto à memória e identidade; a comensalidade e sua transmissão ou mesmo as questões das tradições inventadas que vem através da gastronomia para compor espaços turísticos/culturais. Utilizando palavras de Regina Abreu (2005, p.37), isso pode ser a "patrimonialização das diferenças culturais".

Da culinária do Marolo, se fazem geleias, sorvetes, doces, compotas, vinhos, licores, suco, iogurte e produtos de panificação. A fruta é consumida "in natura”, mas as famílias que colhem com o objetivo de comercializá- 
la, também produzem polpa como estratégia de conservação (congelamento) e como modo de facilitar sua venda junto a padarias, lanchonetes e sorveterias.

Pela culinária percebe-se um conjunto de procedimentos e de valores simbólicos que expressam particularidades de grupos sociais e traduz as influências ideológicas, étnicas, socioeconômicas, dentre outras (DIEZGARCIA, CASTRO, 2011). Os relatos abaixo evidenciam essas situações, que fazem do Marolo uma importante fruta para esse grupo:

"Não levo doces, só levo o Marolo mesmo. Ah, levo a polpa também, quando eu tenho encomenda de polpa lá, que o pessoal pega pra fazer sorvete. Aí eu levo a polpa pronta, entrego e vendo o Marolo na feira" (P, vendedora).

"Com o Marolo a gente faz doce, tira polpa pra fazer doce. Eu mesmo faço o doce e meu irmão vende. Eu faço do tipo mole e de cortar. Aí, ele sai pra vender lá na barraca dele" (M, vendedora).

Dada a relevância da fruta na região, órgãos governamentais como a Empresa de Assistência técnica e Extensão Rural do Estado de Minas Gerais (EMATER), desde 2004, procura incentivar o plantio e a organização de eventos que orientem a população a produção artesanal dos derivados do Marolo. Parcerias interinstitucionais procuram desenvolver estudos sobre propriedades nutricionais, manejo agrícola, avaliação de impacto socioeconômico, objetivando não só a melhoria na qualidade dos produtos vendidos, mas também da qualidade de vida para as famílias que têm no Marolo um acréscimo de renda per capta sazonal. Esses trabalhos também geram subsídios que possibilitem pleitear o registro no Instituto Nacional de Propriedade Industrial (INPI), a exemplo de outras regiões brasileiras que possuem produtos gastronômicos com Indicação Geográfica (IG), tais como a cachaça de Paraty; o café da Região do Cerrado Mineiro e os vinhos do Vale dos Vinhedos (RS).

A transformação do alimento em comida, algo cozido, é apreendido culturalmente, sendo registro de uma culinária que estimula as sensações de gosto e olfato experimentados pelo indivíduo junto ao seu grupo social. A alimentação, intimamente vinculada ao sistema sociocultural, apresenta significado de caráter nutritivo, bem como mostra particularidades do comportamento de grupos sociais (DIEZ-GARCIA, CASTRO, 2011).

\section{A percepção nutricional}

O Marolo oferece atrativos sensoriais como cor, sabor e aroma peculiar e intenso, além do elevado valor nutricional, devido aos níveis de açúcares, proteínas, vitaminas e minerais. É rico em carotenóides, polifenóis, tocoferóis, flavonoides (DRAGANO, 2010). Há três variedades conhecidas (vermelho, amarelo e branco) provavelmente relacionadas com a composição e com o teor de carotenoides (COSTA; VIEIRA, 2004; PAULA et al., 2004). De acordo com Roesler et al. (2007), essa fruta apresenta compostos com alta capacidade de sequestrar radicais livres, ou seja, atividade antioxidante. O Marolo 
apresenta ainda teores de vitaminas do complexo $\mathrm{B}$, tais como tiamina, riboflavina e biotina, equivalentes ou superiores aos encontrados em frutas como o abacate, a banana e a goiaba, boas fontes dessas vitaminas (DELLA LUCIA, 2013).

Os usos tradicionais de Marolo na medicina popular incluem o tratamento de feridas, doenças venéreas, acidentes ofídicos, piolhos e doenças degenerativas, bem como para utilização em ação antimicrobiana, antidiarreico e preparações antitumorais (DRAGANO, 2010). A revelia do conhecimento científico e de sua composição nutricional, algumas características medicinais são mencionadas nas expressões dos entrevistados, mostrando uma fruta rica em vitaminas, "forte" e depurativa.

"Ele (o Marolo) é bom sim, o que tem de mal por dentro sai, certo? Porque ele faz dá espinha. Então quando sai espinha é porque a carne da pessoa por dentro ta meio suja, né? Então, a espinha está limpando, é depurativo. Ele faz limpar mesmo. É igual o inhame" (G, sitiante).

“ [...] mas que eu ouvi falar é que ele é uma vitamina fora de sério, agora não sei pra que, mas que tem vitamina tem" (D, vendedor, produtor).

O significado de depurativo apresentado por nosso informante, quando comparado a outros estudos (CAMPOS, 1982), que trabalharam classificações populares dos alimentos, está mais relacionado à categoria de reimoso ou quente, já que tais alimentos são os responsáveis pelo aparecimento de erupções cutâneas e outras doenças ligadas ao sistema circulatório e digestório - "vindas de dentro do corpo". A despeito dessa significação, as propriedades funcionais do Marolo são atribuídas à presença de compostos com potencial antioxidante.

Sobre essa rede de significados construída socialmente, Campos (1982) demonstra que o sentido atribuído à "fortidão" dos alimentos é uma forma de classificação popular presente em diferentes países. Para a autora, a classificação em forte está relacionada à sequência "trabalho-desgaste físico-fomealimento", ou seja, "a comida forte mata a fome, faz com que se possa passar um longo tempo sem comer, e conseguindo trabalhar" (CAMPOS, 1982, p. 19).

Como apresenta compostos aromáticos de intenso atrativo sensorial (odor, sabor, cor), o marolo é fruta que desperta sentimentos de amor e ódio (adoro ou odeio) da parte de quem degusta seus gomos ou derivados. Sentimentos ditos por todos entrevistados:

"Isso aí, é porque ele é forte e cheira muito, então tem gente que nunca comeu, aí vai comer e estranha. Quem tá acostumado a comer, pode comer dois ou três que não tem nada. Quem nunca comeu estranha, porque fala que o gosto é forte aí dá dor de cabeça, mas não tem nada a vê. Eu já vendi Marolo de caminhão cheio; tinha dia que eu encostava num posto de gasolina pra dormir, e dormia no meio do Marolo. Dormia dentro da Kombi®, dormia junto com o Marolo, juntinho com o Marolo e não tinha nada. Isso aí é costume" ( $\mathrm{D}$, vendedor, produtor).

Existe uma ideia controversa sobre possíveis sintomas e efeitos nutricionais causados pela utilização dessa fruta: "Dizem que dá dor de cabeça quando come muito. Eu não sei não. Diz também que é bom pra curar problema de 
osso, fraqueza" (C, vendedor). Também relatam possíveis propriedades afrodisíacas ou benéficas, outros estabelecem relação maléfica relacionada ao fazer "misturas" com o Marolo. Por exemplo: quando da ingesta de carne, ovo e banana, deve-se evitar o consumo do Marolo, pois "pode causar dores de cabeça".

Na região há boa aceitabilidade para a fruta e seus derivados, com bastante procura em período de safra. Historicamente o Marolo faz parte do imaginário de alternativa alimentar do povo mineiro. Em "Grande Sertão: Veredas", Guimarães Rosa (mineiro) já citava a relevância da fruta como suprimento: "Assim que a matulagem desmereceu em acabar, mesmo fome não curtimos, [...], ainda tinha araticum maduro no cerrado" (GUIMARÃES ROSA, 1994, p. 527).

\section{O sistema produtivo e econômico da fruta}

Deve-se considerar o sistema alimentar como processo que abrange desde o acesso à terra, passando pelos meios de produção, formas de processamento e comercialização, chegando à escolha e consumo do alimento, incluindo os hábitos alimentares individuais e coletivos, a geração e destino dos resíduos.

O Marolo, da família Annonaceae, também da fruta-do-conde e da atemoia, é árvore rústica que frutifica em solos pobres em nutrientes, cerrado, e apresenta nomes curiosos por diferentes regiões: articum, araticum, pinha do cerrado, cabeça-de-negro, panãn, ou como Marolo no Sul de Minas Gerais. O nome
“Ariticum" é de origem indígena, em Tupi significa "fruta mole", já o nome "Marolo" é expressão que indica "cabeça-de-negro". Ao amarelar por baixo, é sinal de que já está maduro. Na sua época, durante os meses de fevereiro a abril, os frutos são coletados com cuidado para não amassar, não sendo comum encontra-los em redes de hipermercados (RIBEIRO, PASCAL, 2005; SOARES et al., 2009).

O extrativismo e o desmatamento para estabelecer a monocultura do café na região interferiram no cerrado onde antes predominava o crescimento nativo dos maroleiros. Seu cultivo é quase inexistente, sendo praticado, quase que exclusivamente, o extrativismo sazonal, procedimento que pode acarretar na extinção de subespécies, como vem acontecendo com o tipo vermelho. Percepção essa evidenciada por entrevistados:

\footnotetext{
"Tenho do amarelo, tenho do branco, mas hoje mais é do amarelo. A qualidade mais é do amarelo, do branco quase não tem. O amarelo é mais saboroso, mais gostoso, mais doce. Tem o vermelho, mas o vermelho não está existindo mais, está acabando com a raça dele, muito difícil achar. É mais o amarelinho madurado assim natural, e ele é gostoso igual o vermelho mesmo" (D, vendedor e produtor).
}

Algumas pessoas procuraram replantar $\mathrm{o}$ Marolo, antes mesmo de órgãos governamentais, incentivarem tal prática. Foram tentativas individuais para preservar a planta do cerrado, que sofreu grande impacto exterminador com a atuação do desmatamento que ocorreu nos anos de 1970. Esse contexto 
político-econômico temporal foi resgatado em entrevistas, como essa:

"Em 1970 a turma estava desmatando (referindo-se ao desmatamento realizado para plantio do café nas grandes fazendas), arrancando o cerrado. Eles estavam levando tudo de lá, arrancando os maroleiros. Aí eu fiquei com dó e falei - Oh, eu que vou plantar um pouco. Meu pai tinha um terreno pra baixo de Paraguaçu que ele vendeu pra desmatar, também pra plantar café. E lá tinha muito Marolo. É desse Marolo de lá que plantei, Marolo bom mesmo" (G, sitiante).

Segundo vendedores do trevo da rodovia de Paraguaçu, existe uma dificuldade progressiva a cada ano de se conseguir o Marolo para vender, o que tem acarretado a necessidade de buscá-lo em outros municípios da região, já que a produção local está reduzida.

"Eu compro lá em São Domingos, porque aqui por perto onde a gente ia comprar, ou buscar no mato, já acabou, não tem mais; aí a gente vai lá, compra e revende aqui no preço" (P, vendedora).

Pode-se perceber que a ocorrência do extrativismo na região (mais de $60 \%$ das coletas), tem gerado escassez da fruta e aberto a possibilidade para atitudes de catas ilícitas, uma vez que a consideram como uma fruta nativa "que ninguém plantou", acarretando desrespeito a propriedades privadas. Alguns produtores reclamaram de saques em suas plantações, executados por pessoas que colhem os frutos antes mesmo de estarem maduros, comprometendo toda cadeia produtiva.

Nas falas dos entrevistados, prevalece uma visão peculiar quanto ao modo de se cultivar o Marolo. Referem-se a ela como uma fruta que não gosta de cuidados, "não gosta nem que mexa com ela" (G. sitiante). Estas colocações se contrapõem a outras concepções, mas a planta subtropical resiste a geadas de até 3 graus.

"Deu bem pouco este ano. Assim, o povo diz que o Marolo, quando não gia, dá menos, dá muito pouco mesmo. Agora quando gia, aí da bastante Marolo" [...] de 2002 pra cá, cortou a metade da florada que dá, por causa que não vinga toda ela mais... o clima mudou, entende? Então ficou muito quente o tempo da florada do Marolo. Então eles abre bastante flor, e por causa do clima ele não conseguiu vingar muito. Tem muito marolinho seco, que não vingou" $(G$, sitiante).

A comercialização se dá de maneira informal, muitas vezes com atravessador, que passa o produto para a pessoa que será o vendedor final. Esse geralmente trabalha com a fruta e com seus doces, vendendo-os na forma artesanal, sem controle sanitário, de forma aleatória, sem ponto fixo: "Não vendo só aqui no trevo da BR, de vez em quando eu vou para a feira de Alfenas. De vez em quando pra Machado" (P, vendedora).

A maioria dos vendedores ambulantes do Marolo são indivíduos de baixa renda. A venda da fruta e seus derivados fornece alternativa de recurso financeiro extra em períodos de safra, melhorando a renda percapta das famílias. A sensibilização e mobilização desses grupos para percepção e resolução de problemas envolvidos na produção e comercialização do produto são salutares. Parcerias formadas entre EMATER, universidades, prefeituras, cooperativas e associações têm permitido a transferência de 
tecnologia e conhecimento para esses grupos, possibilitando melhorar a relação de geração de trabalho e renda, bem como ampliado a relação da fruta e atividades culturais na região.

\section{Como conclusão}

$\mathrm{O}$ estudo mostrou que "trabalhar com o Marolo" segue tradição familiar e os conhecimentos são passados de geração a geração, com toda a família envolvida da colheita até a comercialização dos produtos.

O frágil sistema produtivo, com predomínio extrativista, apresenta atravessadores em que alguns por entenderem que é fruta nativa do cerrado ("ninguém plantou"), fazendo produtores reclamar de saques em suas fazendas, colhendo os frutos antes do tempo, comprometendo a cadeia produtiva.

O valor cultural do Marolo é re-significado pelas pessoas como patrimônio da cidade, e ao mesmo tempo tem seu caráter econômico para famílias de baixa renda. Em Paraguaçu (MG), ele é considerado símbolo de patrimônio cultural e seus habitantes são carinhosamente chamados de "maroleiros". Anualmente acontecem festivais musicais, feiras gastronômicas, mostras culturais, premiações escolares, todos sobre o tema Marolo, tornando os "maroleiros" símbolo dessa cidade.

Nessa perspectiva nosso trabalho foi mais uma provocação para que novas investigações se façam no sentido de organizar as razões culturais que levam grupos sociais a buscar transformar questões culinárias de um dado alimento em patrimônio cultural para sua região. $\mathrm{O}$ que esses grupos revelam ao estabelecerem esse tipo de relação com o alimento?

\section{Referências Bibliográficas}

ABREU, R. Quando o campo é o patrimônio: notas sobre a participação de antropólogos nas questões do patrimônio. Sociedade e Cultura, V.8, N.2, p.37-52, JUL./DEZ. 2005.

AGUIAR, W.M.J.; OZELLA, S. Apreensão dos sentidos: aprimorando a proposta dos núcleos de significação. Revista Brasileira de Estudos Pedagógicos. Brasília, v. 94, n. 236, p. 299-322. 2013.

BRAGA, V.. Cultura Alimentar: contribuições da antropologia da alimentação. Saúde em Revista, Piracicaba, 6(13): 37-44, 2004.

CAMPOS, M.S. Poder, saúde e gosto. São Paulo: Cortez, 1982.

CARDIM, F. Tratados da terra e gente do Brasil. Rio de Janeiro: J. Leite e Cia., 1925.

COSTA T. A, VIEIRA R. F. Frutas Nativas do Cerrado: Qualidade Nutricional e Sabor Peculiar. Disponível em:http://www.todafruta.com.br. Acesso em: out.2004.

DELLA LUCIA, F., AZEVEDO, L., REZENDE, M. L., Pólo, M., MARTINS, M. R.. Marolo (Annona Crassiflora Mart.): gerando trabalho e renda. Extensio: R. Eletr. de Extensão, Florianópolis, 8 (11): 81-91, 2011.

DELLA LUCIA, F. Qualidade do Marolo (Annona crassiflora Mart.) in natura e minimamente processado. Doutorado em Ciência dos Alimentos - Universidade Federal de Lavras/UFLA. 2013 
DIEZ-GARCIA, R. W., CASTRO, I. R. R. A culinária como objeto de estudo e de intervenção no campo da Alimentação e Nutrição, Rev. Cienc. \& Saúde Coletiva, 16(1):91-98, 2011.

DRAGANO, N. R. V. et al. Influence of Marolo (Annona crassiflora Mart.) Pulp Intake on the Modulation of Mutagenic/Antimutagenic Processes and Its Action on Oxidative Stress In Vivo. Plant Foods for Human Nutrition (Dordrecht), v. 65, p. 319-325, 2010.

GEERTZ, C. A Interpretação das culturas. Rio de Janeiro: LTC - Livros Técnicos e Científicos editora, p. 323, 1989.

GUIMARÃES ROSA, J. Grande Sertão: Veredas. Bibl. Luso-Brasileira: série brasileira. Nova Aguilar, vol II. 1994.

MARTINS, H. H. T. S. Metodologia qualitativa de pesquisa. Educação e pesquisa, São Paulo, v.30, n.2, p.289-300, maio/ago. 2004.

PAULA, N. R. F. et al. Caracterização física e química da polpa do Marolo (Annona coriaceae) da região Sul de Minas Gerais, 2004.

PRADO, G. Paraguaçu - sua história, sua gente. CD-Rom, 2004, pela Fundação Dezoito de Março (FUNDAMAR).

RIBEIRO, M. N. O., PASCAL, M.

Tecnologia na produção do marolo. Boletim técnico. Lavras (MG): UFLA, n. 129, p.1-57. 2005.

ROESLER, R. Atividade antioxidante de frutas do cerrado. Ciênc. Tecnol. Aliment., v.27,n.1, p.53-60. 2007.

SELAU, Maurício da Silva. História Oral: uma metodologia para o trabalho com fontes orais. UFSC. Florianópolis-SC: Rev. Esboços, v.11, n.11, p. 217-228. 2004.

SOARES, F. P., PAIVA, R. NOGUEIRA, R. C., STEIN, V. C., SANTANA, J. R. F.

Marolo: uma frutífera nativa do cerrado.
Boletim Técnico. Lavras (MG): Universidade Federal de Lavras (UFLA), Dep. de Biologia; n. 82, p.1-17. 2009.

VYGOTSKY, L.S. A formação social da mente. São Paulo: Martins Fontes, 1991.

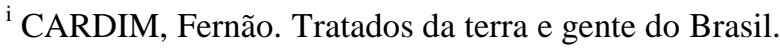
Rio de Janeiro: J. Leite e Cia., 1925. Pe. Fernão Cardim (1550-1625) - jesuíta que chegou no Brasil em 1583. Escreveu três tratados (o primeiro foi Do clima e Terra do Brasil) posteriormente compilados em um único volume chamado "Tratados da terra e gente do Brasil" em 1925.

${ }^{\text {ii }}$ Foi registrado o modo de fazer do licor e de doces de Marolo de Paraguaçu (MG), por meio do decreto n. 94, de 11/12/2009, inscrito no livro de "Registro de Saberes", sujeito a proteção de acordo com a Lei Municipal de 16/10/2009, tornando as receitas patrimônio imaterial.

iii O Ministério da Cultura promulgou o Decreto n. 3551/2000, instituindo o "Registro de Bens Culturais de Natureza Imaterial" que constituem patrimônio cultural brasileiro, criando o "Programa Nacional do Patrimônio Imaterial". O "registro dos bens culturais de natureza imaterial são quatro livros: o Livro do Registro dos Saberes (para registro de conhecimentos e modos de fazer); o Livro das Celebrações (de festas, rituais e folguedos); o Livro das Formas de Expressão (inscrição de manifestações literárias, musicais, plásticas, cênicas e lúdicas) e o Livro dos Lugares (para inscrição de espaços onde se concentram e reproduzem práticas culturais coletivas)" (ABREU, 2005, p.48). 